\title{
A study on the ideal structure of feed sprue in the investment casting process
}

\author{
Kwang-Yeol Lee ${ }^{\dagger}$ \\ Department of JewelryDesign, Korea Women Polytechnic, Ansung 456-719, Korea
}

(Received February 16, 2012)

(Revised February 20, 2012)

(Accepted March 9, 2012)

\begin{abstract}
Maintenance training is generally provided to teach employees new knowledge and techniques in order to increase their qualities.It means that the purpose of maintenance training is to increase an employee's knowledge or technique level and to maintain or increase their performance level through continuous training in their field, and the methods, contents and the level of training vary depending on the type of job they perform. Maintenance training is more important for jobs that require continuous technical increases or research, or for professional jobs that continuously require new knowledge and techniques. The purpose of this study is to provide quality service to consumers by responding to the rapidly changing jewelry distribution environment and to quickly and accurately acquire new and advanced jewelry inspection and appraisal techniques, and to contribute to the healthy consumption culture through a general quality increase in the jewelry industry.
\end{abstract}

Key words Investment casting, Sprue, Liquid metal, Turbulence

\section{정밀주조 프로세스에서 피드 스프루의 이상적 구조에 관한 연구}

이광열 ${ }^{\dagger}$

한국폴리텍여자대학 주얼리디자인과, 안성, 456-719

(2012년 2월 16일 접수)

(2012년 2월 20일 심사완료)

(2012년 3월 9일 게재확정)

요 약 정밀주조기술은 수공예에 의한 일품장신구가 규격화, 표준화된 제품으로 대량 생산될 수 있는 기틀을 만들어 주었고 또한 생산라인의 시스템 개선으로 업무의 분업화와 장비의 첨단화로 명실상부한 장신구가 산업으로서의 면모를 갖 추는데 지대한 기여를 하였다. 본 연구자는 주조장비가 국내 도입된 이래 약 30 여 년 동안 주조장비의 고급화와 업그레이 드에 따른 제품의 질이 향상되었다고 볼 수 있으나 주조장비가 $100 \%$ 해결해 줄 수 없는 생산 프로세스를 직시하면서 정 밀주조 과정에서 매우 중요하다고 판단되는 왁스트리(Wax Tree)공정 시 수행되는 장신구 사출물과 금속이 용해되어 흘러 들어가는 스프루(Sprue)의 연결은 여전히 수작업에 의해 진행이 되고 있고 이 과정에서 원하는 결과물이 나오는데 많은 영 향을 미칠 수 있다는 문제점을 실험데이터를 바탕으로 하여 좀더 완벽한 정밀주조의 프로세스를 수행하기 위한 방안 제시 를 하고자 한다.

\section{1. 서 론}

\section{1. 연구배경}

정밀주조(investment casting)는 그 결과물의 질을 향 상시키기 위한 방법들로 새로운 주조장비의 개발과 도입

\footnotetext{
Corresponding author

Tel: +82-31-650-7265

Fax: +82-31-650-7265

E-mail: gemer1@kopo.ac.kr
}

으로 많은 발전이 이뤄졌으며 그 결과 장신구의 대량생 산 및 질적 효율성과 함께 높은 경제적 부가가치를 창출 하고 있다.

본 연구는 정밀주조의 기계적 문제를 해결하기 위한 접근성은 지속적인 주조장비의 품질 향상으로 이어질 것 이나, 주조형태를 인위적으로 개선할 수 있는 구조(디자 인) 측면에서의 문제해결 접근성은 많은 연구가 필요하 다는 전제를 가지고 주조 결과물에 중요한 결함요소가 될 수 있는 스프루(Sprue)의 형태에 대하여 연구를 하고 자 하며 연구방법은 데이터 실험을 통하여 개선방법을 
제시하고자 한다.

\section{2. 정밀주조에서 스프루의 역할}

정밀주조에서 스프루(sprue)시스템의 역할은 왁스 트리 가 매몰 될 때까지 왁스 패턴이 적절한 위치를 잡을 수 있도록 잡아 주는 것이며, 왁스가 매몰 몰드 밖으로 원 활이 빠져 나갈 수 있도록 길을 제공하는 것이다.

또한 연소 후 스프루는 용탕 금속이 패턴의 공간 속으 로 원활이 들어갈 수 있도록 통로를 제공하며, 훌륭한 구조는 용탕 금속의 요동(turbulence)과 용탕(liquid metal) 이 관을 통과하는 동안의 열 손실을 컨트롤 할 수 있어 야 할 것이다.

용탕의 요동은 정밀주조에 있어서 가장 신경 써야 할 요소 중의 하나 이며, 요동은 금속이 가스를 흡수하여 금속 내 외부로 혼입시킬 수 있고, 열 손실을 가속화 시 킬 수 있다. 이러한 요동을 피할 수 없다면 최소화 시켜 야 할 것이다.

일반주조와 달리 정밀 주조는 많은 경험과 실험을 통 하여 요동의 감소는 원형 스프루가 일반 적인 직선 스프

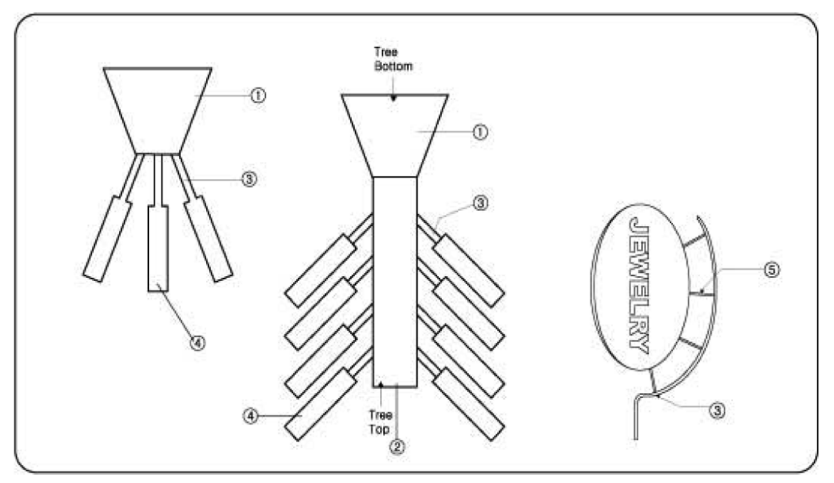

Fig. 1. Gate and sprue of composition.

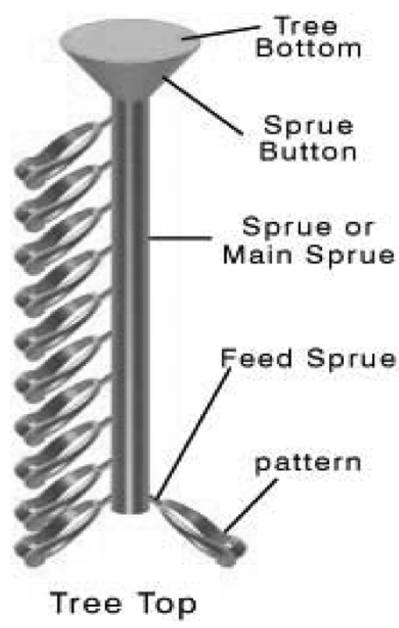

Fig. 2. Sprue design.
루보다 훨씬 뛰어나다는 것이 이미 학자들의 연구 자료 를 통해 검증이 된 사실이며 직선형 테이퍼 스프루에서 는 $1.1: 1$, 곡선형 테이퍼 스프루에서는 $1.3: 1$ 이상이 요동의 감소에 적당 하다는 것이 일반화 되어 있다.

이는 스프루게이트(Gate)에서 메인 스프루까지의 통로 는 디자인에 따라 요동을 유발할 수도 감소시킬 수도 있 다는 증거이기도 하다.

(1) 탕구(GATE, POURING)

(2) 탕도 봉(SPRUE, MAIN SPRUE, DOWN SPRUE or CENTER SPRUE)

(3) 피드 스프루(FEED SPRUE)

(4) 제품(PATTERN, CAST)

(5) 2 차탕도, 또는 보(RUNNER)

\section{2. 본 론}

\section{1. 스프루의 구조이해}

2.1.1. 탕도(Feed Sprue,물줄기)의 여러형태

Fig. 3의 (1)은 현재 업계에서 가장 보편화 돼 있는 형 상으로 탕도 부위는 원주를 유지하고 제품 연결부위는 두들겨서 사각으로 납작하게 한 형태는 요동을 일으키기 쉬우며 공기의 혼입을 가져올 수 있다. 만약 제품 연결 부위를 어쩔 수 없이 두들겨서 연결해야 할 경우는 사각 이 아니고 그림 (5)와 같이 제품 연결 단면 부를 타원이 되도록 해야 한다.

(2)의 경우가 가장 바람직하다고 할 수 있다. 탕구와 제품 연결부의 원주의 굵기가 같은 경우이다. 그림 (3)과 (4)는 유속의 변화를 주고 요동을 감소 시킬 수 있는 형 태로, 런너(Runner)또는 피드스프루의 적용에는 제품의 형태에 따라 적용하는 경우가 있으나 신중한 계산과 연 구가 필요하다.

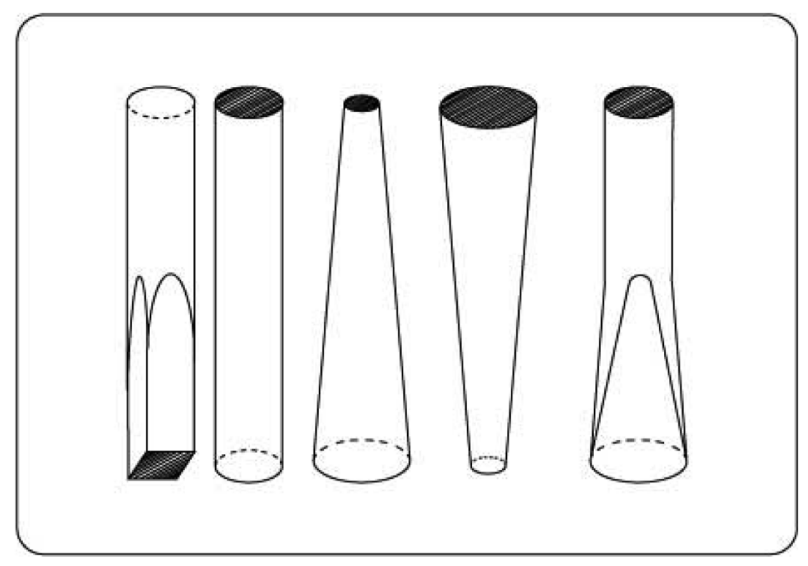

Fig. 3. Sprue of composition left (1) (5). 


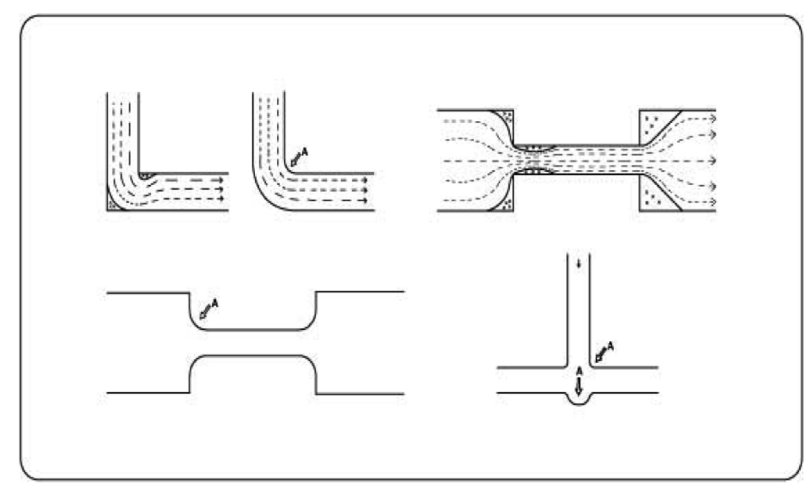

Fig. 4. Gate a way (1).

\subsection{2. 용탕의 흐름과 요동(Turbulence)}

탕도가 직각인 경우 꺽인 안쪽 부위에서 용탕이 유입 될 때 난류(㒀流)를 발생시켜 잔류공기가 혼입되므로 직 각 부위를 탕도의 구조에 맞게 곡선으로 처리하는 것이 불량을 줄이는 중요한 요소이다.

또한 Fig. 4의 표시부분과 같이 탕도를 통해 들어온 쇳물(용탕)이 각각의 탕도로 분리되기 전 부딪치는 부위 를 둥글고 오목하게 하여 용탕이 튀거나 역류저항을 완 화 시키는 것이 중요하고 용탕의 요동은 품질의 적이며 피할 수 없다면 최소화 시킨다.

Fig. 5의 A 및 B: 주입시간이 짧고 주조 시 금(Gold) 의 결손(LOSS)이 적은 반면 가스 및 불순물의 유입이 결함으로 나타날 가능성이 크다.

$\mathrm{C}$ : $\mathrm{A}$ 및 $\mathrm{B}$ 의 결점을 보완한 방법

$\mathrm{D}$ : Center Sprue를 설계한 방법으로 제품표면이 양호 하며 결함을 최소한으로 할 수 있다 금의 결손이 다소 큰 것이 단점이다.

\subsection{3. 스프루(Sprue)의 형태 "V"와 "Y" 방법}

(1)과 (2)는 탕도의 굵기가 같기 때문에 Fig. 6의 부위 (A)에 용탕의 유입 압력과 배압에 의하여 기포 또는 용

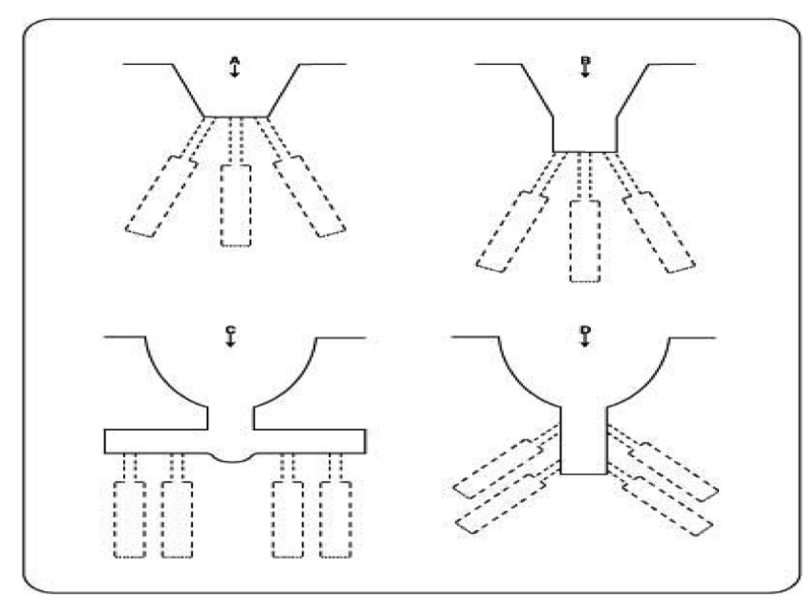

Fig. 5. Gate a way (2) A D.

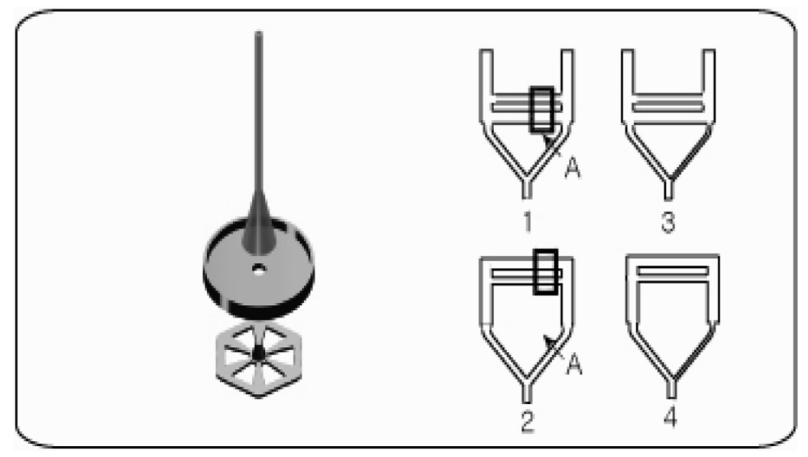

Fig. 6. Sprue V, Y design.

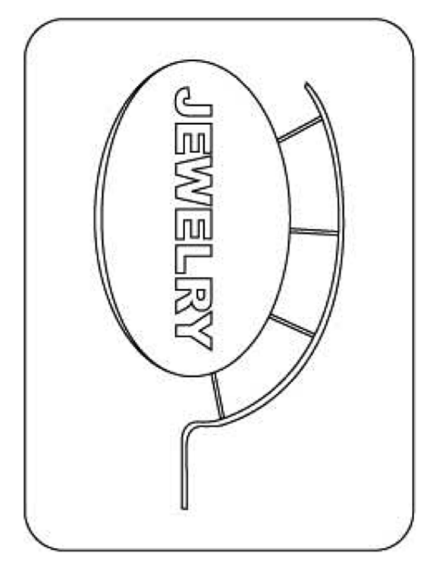

Fig. 7. The second design.

탕의 미 주입에 의한 침식 결함 등이 발생 할 수 있으 므로 (3) 또는 (4)와 같이 좌(左), 우(右)의 탕도 굵기를 달리하여, 압력 및 용탕의 흐름 속도를 달리하므로 우수 한 제품을 얻을 수 있다.

\subsubsection{2차 탕도와 보(Runner)}

보는 메인 스프루에서 비롯되며 여러 패턴 혹은 한 패 턴에서 여러 포인트에 부착되는 몇 개의 피드스프루 (Feed Sprue)를 가지고 있다.

보는 일반적으로 끝까지 채워지게 주입되고, 용탕이 피드스프루에 주입될 때 배압이 발생한다.

Fig. 7. Runner가 적절히 사용되어진 사례이며 테이퍼 런너(Tapered Runner)와 피드스프루들은 패턴(Pattern)까 지 도달하는 시간을 획기적으로 줄여 주며 완벽한 주물 을 얻을 수 있다.

\section{2. 탕도의 일반적 사례}

\subsection{1. 상부(머리, Head)가 큰 형태}

Fig. 8의 세가지 형태 중 왼쪽은 가는 지륜(指輪, shank), 상부는 크고, 두텁다(heavy) 그리고 가늘고 단면적이 작 은 스프루가 밑에 붙어 있는 형태로 이대로 주조하면 상 


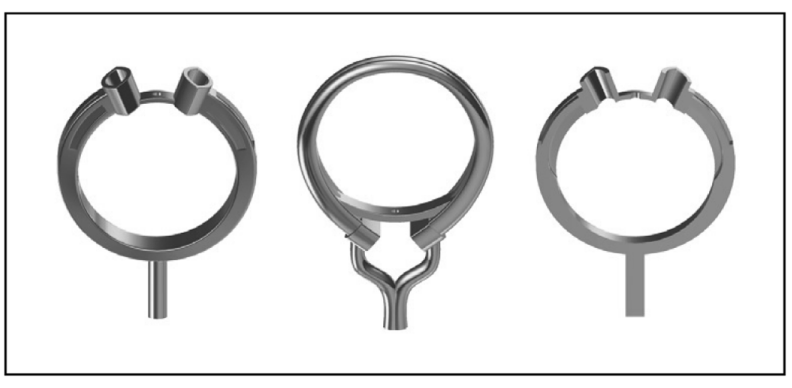

Fig. 8. Big head ring gate design.

부에 많은 기포들이 발생한다.

사진 중앙의 경우처럼 두 개의 피드스프루를 부착하여 이를 통하여 두꺼운 부분으로 흘러 들게 하는 것이 훌륭 한 주조가 이루어 질 수 있고 형태가 수정될 수 있다면 상부 는 속이 빈(hollowed out) 상태로 하는 것이 좋으 며, 지륜 부분(Shank)부분은 사진의 오른쪽 처럼 두텁게 하는 것이 좋다.

아래의 경우 또한 좋은 주조 결과를 얻기 위한 방법이 며, 최근 일본에서 주조가 어려운 큰 제품의 경우 시행 하고 있으며, 좋은 경과가 얻어지고 있다.

결론적으로 피드스프루를 밑 부분은 부텁게 부착하고, 모든 파라미터가 정확하다면 항상 훌륭한 주조물을 얻을 수 있다.

\subsection{2. 스프루의 형태 $\mathrm{V}$ 와 $\mathrm{Y}$ 방법 적용 예}

복잡한 패턴에서 용탕의 흐름을 고려하여 " $\mathrm{Y}$ " 형상으 로 피드스프루 겯 부착시 주의를 기울여야 한다.

메인 스프루로부터 “Y”의 중심줄기(Stem)는 1차 피드 스프루가 되고, 갈라지는 2 개의 2 차 피드스프루에 용탕 이 공급되어질 수 있도록 충분한 교차공간(cross sectional area)을 갖게 설계한다.

침식은 급격한 에지(edge)부분을 용탕이 통과하면서 발생함으로 스플릿(Split) 내부를 모나거나 각지지 않고 둥글게 만든다.

용탕과 매몰 플라스크 간의 온도차이가 크면 침식에 의한 결함이 발생하기 쉽고, 특히 화이트골드, 팔라듐 주 조 시 이러한 결함은 더욱 크게 발생한다. 용탕이 $\mathrm{Y}$ 형 태의 두 개의 2 차 피드 스프루로 갈라지는 곳의 요동 (turbulence)은 "V" 형태를 이용하여 완화 시킬 수 있다. 다른 변수가 일정 하다면 " $\mathrm{V}$ " 스프루는 " $\mathrm{Y}$ " 스프루 보 다 온도의 손실을 최소화 하며 용탕(Meral)을 패턴전체 에 완벽하게 도달 시킬 수 있다. 그 이유는 용탕의 진로 (Path)가 최단이고, 탕경 압력을 이용한 테이퍼스프루를 적용 했기 때문이다. 하지만 메인 스프루에 왁스 패턴 부착 작업이 $\mathrm{Y}$ 스프루 패턴 부착 작업보다 번거로운 단 점이 있다.

"V" 형태나 "Y" 형태의 스프루는 균형 잡힌 유체 시

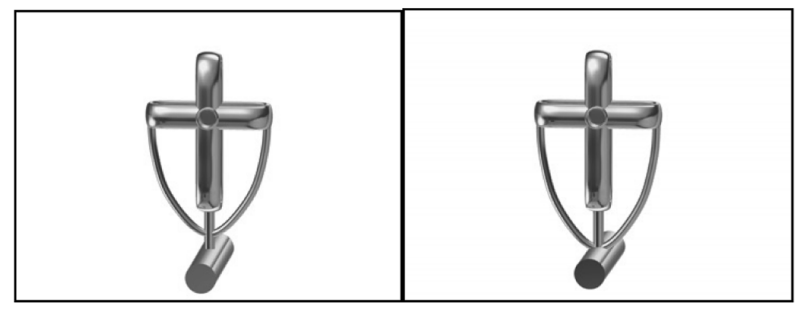

Fig. 9. V, Y shape sprue design.

스템(Fluid System) 이라서 원심력과 같은 외부의 힘이 작용하지 않는 한 두 갈래로 갈라지는 분기점에서 균등 한 분할을 유지 시키는 것이 중요하다. 또한 2 차 스프루 를 테이퍼 디자인으로 하여 용탕 흐름 방향에 직각인 십 자가의 팔 부분에 부착시킴으로 용탕의 흐름을 빠르게 하고, 고체화 될 때 온도 유지시간을 같게 하여 완벽한 제품을 얻을 수 있다.

\subsection{3. 크기 두께가 다른 패턴의 혼합 주조}

앏고 섬세한 패턴을 정밀하게 주조할 수 있을 정도로 온도가 높다면, 동일한 트리의 크고 두꺼운 패턴에게 너 무 높은 온도이기 때문이다. 얇은 패턴은 트리의 꼭대기 (Top)에서 잘 주입 된다. 이유는 바닥에서의 압력보다 꼭대기에서의 압력이 더 높기 때문이다.

얇은 패턴이 트리의 꼭대기에서 잘 주입되지 않는다면 피드스프루가 작거나, 패턴에 적합하게 연결되지 않았거 나, 매몰 플라스크 온도가 너무 낮은 경우이다.

어쩔 수 없이 동일 플라스크에서 혼합 주조할 경우는 꼭대기에서 보다 더 공격적(challenging)인 디자인과 바 닥(Bottom)에서 주입하기 쉬운 패턴이 혼합 되어질 수 있다.

즉 얇고 섬세한 패턴은(Top)에, 두껍고 큰 패턴은 바 닥(Bottom, 탕구) 쪽으로하여 피드스프루의 크기, 위치

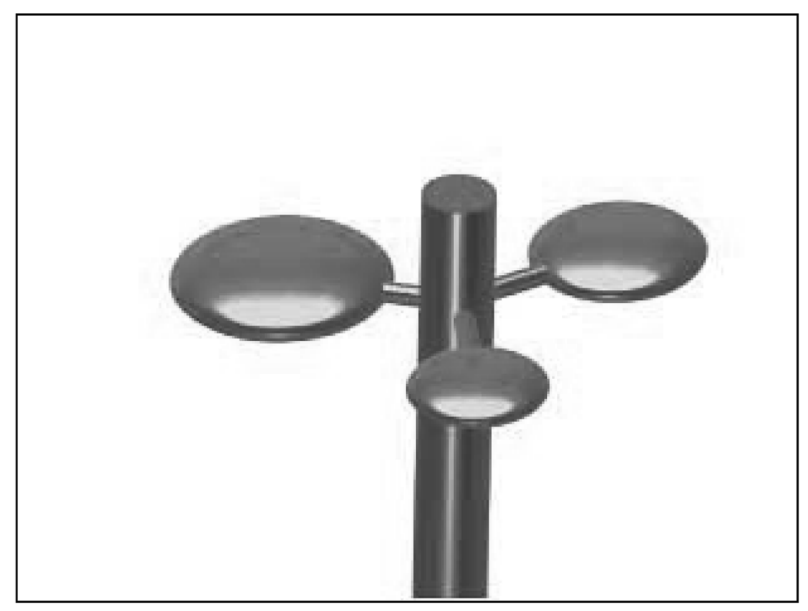

Fig. 10. Size, thick different investment design. 
Table 1

Pattern an area volume

\begin{tabular}{llll}
\hline Pattern size & $\begin{array}{l}\text { Total surface } \\
\text { area } \mathrm{mm}^{2}\end{array}$ & $\begin{array}{l}\text { Increase heat } \\
\text { over 1 mm thick }\end{array}$ & $\begin{array}{l}\text { Percent increased } \\
\text { surface area over } \\
1 \mathrm{~mm}\end{array}$ \\
\hline $15 \times 15 \times 1$ & 510 & $0 \mathrm{x}$ & $0 \%$ \\
$15 \times 15 \times 2$ & 570 & $2 \mathrm{x}$ & $11 \%$ \\
$15 \times 15 \times 4$ & 690 & $4 \mathrm{x}$ & $27 \%$ \\
\hline
\end{tabular}

플라스크의 온도와 용탕 금속의 온도를 신중히 고려하여 야 한다.

Fig. 10 과 같이, 예를 들어 $15 \times 15 \mathrm{~mm}$ 와 $1,2,4 \mathrm{~mm}$ 의 각 각 두께를 가진 세종류의 패턴이 있다면, 동일 트 리에서 주조 조건(매몰재 플라스크, 용탕온도 등등) 은 세가지 모든 패턴에 동일하게 작용한다.

세가지 패턴의 윗면과 바닥 면의 표면적은 동일하고 측면의 두께만 다르므로 좀더 커다란 패턴에서 표면이 늘어나는 것은 측면(side)뿐이다. 그리고 위, 아래 표면 적보다 측면이 더 빨리 볼륨이 증가하게 된다.

용탕으로 부터 플라스크 매몰 재로의 모든 열 손실은 표면경계(Surface interface)를 통하여 이루어지며 패턴에 의해 얻어진 부피가, 용탕의 금속이 주조될 때, 용탕의 온도는 인접한 부분에만 온도변화를 줄 수 있다.

따라서 플라스크 매몰재의 $1 \sim 1.5 \mathrm{~mm}$ 두께에만 온도변 화를 줄 수 있고 자연적으로 메탈이 굳어감에 따라 인접 한 매몰재는 열을 얻게 될 것이다.

그리고 각 패턴은 패턴의 두께에 따른 메탈의 양과 열 에너지의 상대수치를 갖게 되며 $4 \mathrm{~mm}$ 두께의 패턴은 $1 \mathrm{~mm}$ 패턴의 4배에 달하는 열을 방출한다.

즉, 이것의 의미는 $1 \mathrm{~mm}$ 혹은 $2 \mathrm{~mm}$ 패턴주변에서 보 다 $4 \mathrm{~mm}$ 패턴주변에서 훨씬 더 높은 플라스크 매몰재 의 온도가 상승할 수 있다.

가령 $1 \mathrm{~mm}$ 패턴을 기준으로 용탕 온도와 플라스크 매 몰재 온도를 정확하게 설정 했다면, $1 \mathrm{~mm}$ 보다 두꺼운 $2 \mathrm{~mm}, 4 \mathrm{~mm}$ 이상의 제품은 주조가 매우 어렵다. 높은 온도는 두꺼운 패턴에 있어서 가스 기공 등의 결함을 발 생 시킬 수 있기 때문이다.

\section{3. 시스템 온도와 주조의 상관관계}

시스템 온도(System temperature)는 표면적과 볼륨 비 율에 대하여 표면적(Surface area)이 가지는 용탕의 냉각 과 특정패턴, 플라스크의 온도, 용탕의 온도, 스프루 및 합금금속의 상호작용과 주조시 온도상승 수반요인과 결 과를 분석하여 최적의 온도를 표준화 하는 것이다.

표면에 홈(groove)이 있는 패턴은 $4 \mathrm{~mm}$ 패턴의 두께 와 마찬가지로 메탈의 볼륨(체적)은 그다지 크지 않을 수 있고 표면적만이 좀더 크다고 할 수 있다. 통상적으
로 작업자들은 "medium flask 온도"에서보다 더 양호하 게 주조할 수 있다고 판단 하는데, 다음과 같은 결론을 얻을 수 있다.

\subsection{1. 시스템 온도의 패턴 특징}

크기가 다른 패턴을 동일한 트리(tree)에서 주조 하는 점을 감안할 때, 교차범위의 두께뿐 아니라 표면(surface) 에 대한 볼륨 비율(Volume ration)을 알 수 있다.

패턴의 큰 표면적과 작은 볼륨(얇은 패턴)의 형태일때, 플라스크의 온도 영향이 용탕 온도의 영향보다 크다.

볼륨은 단면적에 대하여 비례함에 따라 플라스크 온도 영향은 크고, 시스템 온도를 어렵게 하며 플라스크 온도는 패턴 트리에 대하여 주조 주입의 원활할 지가 결정된다.

얇은 패턴과 두꺼운 패턴이 같은 트리에 있을때, 플라 스크의 온도는 얇은 패턴에 대하여 설정하여 주조하기에 충분한 고온이나, 두꺼운 패턴에 있어서는 너무 고온 이 어서 최적의 상태가 되지 못한다.

\subsection{2. 시스템 온도의 지금 합금과 알로이 특성}

용탕의 주조 온도는 용탕의 온도보다 다소 높거나 같 아야 하고, 다양한 합금들이 각각 다른 온도에서 녹기 때문에 주조 온도 역시 다양하다(알로이에 있어서도, 두 꺼운 부분의 패턴에 대해서 주조온도는 일반적으로 낮고, 얇은 패턴에 대하여는 고온이다.)

그러나 주조에 있어서 중요한 것은 주조시 플라스크의 온도만이 아닌 패턴 사이즈, 디자인, 피드스프루의 연결 부분에 의하여도 영향을 받는다.

따라서 계산된 피드스프루 디자인을 통하여 보다 낮은 온도에서도 주조가 가능하다.

\section{4. 시스템 온도 테스트(System Temperature Test) 및} 분석

간단한 실험으로 특정 알로이의 패턴 범위(Range)를 위한 최적의 시스템 온도를 찾아낼 수 있다.

Fig. 11과 같이 먼저 5 6종류의 다른 패턴으로 다섯 개의 트리를 만들고 주조실험의 패턴을 thin, medium, thick, large and small 등으로 구분하고 트리에 심기 전 에 모든 왁스패턴 을 점검하고, 같은 위치에 붙인다.

패턴들은 메인 스프루의 top, center, bottom에 수직으 로 위치하게 부착하며 이 실험의 목적은 각 패턴이 각각 의 온도 조합(temperature combination)에서 어떻게 주 조가 되는지를 찾아내는 데 있다.

만일 트리에 다섯 개의 패턴이 있다면 각 각의 다른 패턴들이 설정된 온도에서 어떤 조건이 좋은 것인가를 확인할 수 있다.

이것을 계획실험(designed experiment)라고 부르며, 왜 


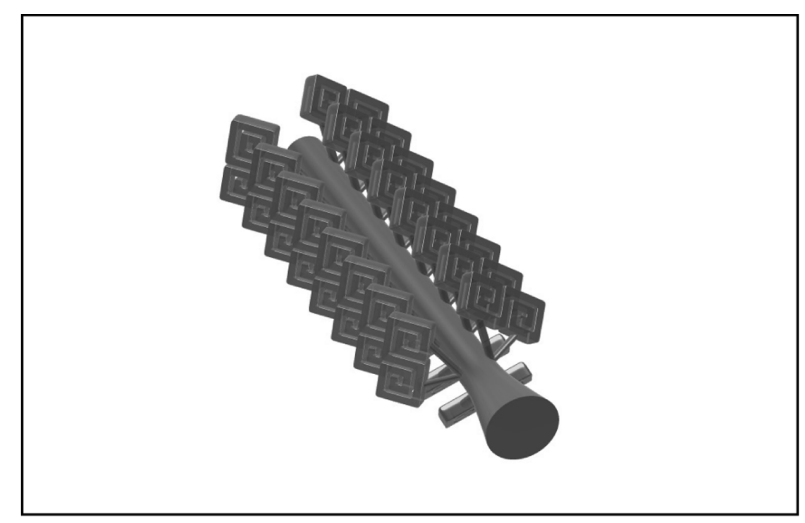

Fig. 11. Different investment patten.

Table 2

System temperature test grid

\begin{tabular}{llll}
\hline \multicolumn{3}{l}{$\begin{array}{l}\text { System temperature test grid } \\
\text { Date:2010/03/20 } \\
\text { Patterns Tested 1,2 }\end{array}$} \\
\hline $\begin{array}{llll}\text { Matal } \\
\text { temperature }{ }^{\circ} \mathrm{C}\end{array}$ & \multicolumn{3}{c}{ Flask temperature ${ }^{\circ} \mathrm{C}$} \\
\cline { 2 - 4 } & 500 & 550 & 600 \\
980 & & Flask2 & \\
1000 & Flask1 & Flask3 & Flask5 \\
1020 & & Flask4 & \\
\hline
\end{tabular}

계통적 테스팅 공정(methodical testing process)이 손쉬 운 방법인지를 설명하여 준다.

이 방법은 플라스크의 테스트그리드(Test Grid Grid) 와 메탈 온도를 이용하여 주조하고 어떤 형태의 주조를 할 것인지 알아야 한다.

Table 2는 시스템 온도 테스트 그리드와 같이 테스트 그리드 중앙(sweet spot)에서 작업하기 쉬운 지점의 온 도를 가정한다.

이 경우, 플라스크의 온도는 $550^{\circ} \mathrm{C}$ 와 메탈의 온도는 $1,000^{\circ} \mathrm{C}$ 이며 테스트 그리드 위, 아래부분, 그리고 SWEET SPOT 각 사이드 부분에서 각 온도 조합(temperature combination)에서 하나의 플라스크로 주조한다.

주조하기 전에 주조 온도에서 플라스크를 충분히 소성 예열하여야 하고 주조 후, 생 주조물(as-cast 生 鑄造物, 기 계 가공을 하지 않은 주조한 그대로의 주물) 상태에서 캐 스팅을 품질 검사하고 결과를 기록하고, 마지막의 일반적 인 품질검사 과정을 거쳐 유용한 데이터를 기록 보관한다.

간단한 검사 기준은 테스트 결과를 평가하기 위한 주 조 등급 결정에 사용되어 진다.

\section{5. 시편제작 및 데이터분석}

\subsection{1. 검사 기준(Inspection Criterion)}

주조 검사가 이루어지고 일반적으로 평가는 1 3등급
으로 나눈다.

1등급: 주조물 상태에서 품질관리에 합격.

$\diamond 2$ 등급: 보완/수정하면 품질관리에 합격.

$\diamond 3$ 등급: 수정할 가치가 없는 불합격품.

대부분의 경우 3 등급은 주조환경과 주조조건(cast condition)이 좋지 않은 상태에서 발생한다.

2 등급 또한 주조 조건과 환경이 좋지 않을 때 발생할 수 있는데 원자재의 불량, 매몰, 소성의 문제 등등의 원 인이며 표면 밑의 결함(Subsurface)이 추후에 나타날수 있다.

주조 전에 왁스 패턴을 주의 깊게 검사하여, 몰드와 왁스 패턴에 영향을 줄 수 있는 결함들은 제거 되어야 한다. 주조를 위한 왁스 사출, 보관, 왁스 트리작업에서 주조 불량의 원인이 될수 있는 것을 철저히 제거하여야 한다. 특히, 왁스 패턴은 기포, 이물질 부착, 파우더 등 이 없어야 한다. 매몰(investment)이나 탈 왁스(burnout), 플라스크 소성에 영향을 줄 수 있는 결함을 찾아내는데 주의를 기울여야 한다.

이 실험에서 매몰재 및 매몰의 작업불량, 매몰된 플라 스크의 관리 부주의에 의한 크랙, 파손 물결(fin)결함, 매 몰재의 함유 등으로 작업자의 부주의에 의해 발생하는 결함은 온도에 의한 주조결함에 관련이 없다. 즉, 평가로 부터 제외 시켜야 한다.

주조 후 잘못된 시스템 온도(wrong system temperature) 의 대표적인 결함들을 요약하면, 불충분한 주입(incomplete filling), 가스기공(gasporosity), 수축기공(shrinkage porosity), 함몰, 거친표면, 균열 등이 있다.

주조의 평가 후, Table 3 시스템 온도 테스트 결과와 같이 각 패턴에 $1 \sim 3$ 등급으로 테스트 결과를 구분한다. 테스트 데이터는 쉽게 이해할 수 있으며, 추세도 쉽게 알아볼 수 있도록 되어 있다.

Table의 결과를 보면 합금 $18 \mathrm{k}$ 의 주조패턴에 가장 적 합한 플라스크 온도와 주조 온도를 나타낸다. 패턴 1 은 표면 볼륨에 대한 비율을 판단하기 위하여 패턴의 넓은 부분을 선택하였다.그러므로 유사한 플라스크 온도와 주 조 온도에서 훌륭히 주조가 이루어질 수 있을 것이다.따

Table 3

Pattens 1 system temperature test results chart

\begin{tabular}{|c|c|c|c|}
\hline \multicolumn{4}{|c|}{$\begin{array}{l}\text { System temperature test results chart } \\
\text { Date: } 2010 / 03 / 20 \\
\text { Patterns Tested } 1 \\
\text { Alloy: } 18 \mathrm{k}\end{array}$} \\
\hline \multirow{2}{*}{$\begin{array}{l}\text { Matal } \\
\text { temperature }{ }^{\circ} \mathrm{C}\end{array}$} & \multicolumn{3}{|c|}{ Flask temperature ${ }^{\circ} \mathrm{C}$} \\
\hline & 500 & 550 & 600 \\
\hline 980 & \multirow{3}{*}{$2 / 3 / 3$} & $1 / 1 / 1$ & \multirow{3}{*}{$3 / 3 / 3$} \\
\hline 1000 & & $1 / 2 / 2$ & \\
\hline 1020 & & $2 / 2 / 2$ & \\
\hline
\end{tabular}


Table 4

Pattens 2 system temperature test results chart

System temperature test results chart

Date: $2010 / 03 / 20$

Patterns Tested 2

Alloy: 18k

\begin{tabular}{llll}
\hline \multirow{2}{*}{$\begin{array}{l}\text { Matal } \\
\text { temperature }{ }^{\circ} \mathrm{C}\end{array}$} & \multicolumn{3}{l}{ Flask temperature ${ }^{\circ} \mathrm{C}$} \\
\cline { 2 - 4 } & 500 & 550 & 600 \\
\hline 980 & & $3 / 3 / 3$ & \\
1000 & $3 / 3 / 3$ & $2 / 2 / 2$ & $1 / 1 / 3$ \\
1020 & & $1 / 2 / 2$ & \\
\hline
\end{tabular}

라서 패턴1에서 나타난 결과물은 주조온도 $980^{\circ} \mathrm{C}$ 플라 스크 온도 $550^{\circ} \mathrm{C}$ 에서 주조시 좋은 품질의 주조물을 얻 을 수 있음을 알 수 있다.

동일한 주조공정에서 테스트 그리드를 시행하여 결과 가 가장 훌륭한 테스트 온도 그리드를 선택함으로 쉽게 최적의 온도 조건을 찾을 수 있다.

Table 4의 \#2패턴은 테스트 결과가 어떤 방향으로 가야 할지를 나타내며 패턴 2 결과에서는 주조 온도 $1,000^{\circ} \mathrm{C}$ 에 서 플라스크 온도 $600^{\circ} \mathrm{C}$ 가 가장 좋기는 하나 완벽 하지 않은 결과이고 주조온도 $1,020^{\circ} \mathrm{C}$ 까지 올려 테스트를 시 행할 필요성이 있었다.

이런 테스트그리드는 단일 주조 시험으로 할 수 있으 며, 때로는 이미 도출된 테스트그리드를 바탕으로 새로 운 테스트그리드를 시행하므로 최상의 시스템 온도를 표 준화 할 수 있을 것이다.

\subsection{2. 시편제작}

1) 최적의 피드스프루 설계를 위한 시스템 온도테스트 를 통해 최적의 온도 조건을 찾아 내어 생산에 적용하여 도 때로는 선택 되어진 시스템 온도에서 원하는 품질로 주조되지 않을 경우가 있고 이것은 잘못된 피드스프루의 원인일 가능성이 높다.

피드스프루의 테스트 방법으로는 왁스 몰드를 가지고 왁스주입(Wax Injection)시험을 통하여 어느 정도 알 수 있다.

먼저 왁스의 적정 사출온도를 찾고 몰드로부터 분리한 패턴이 거칠게 나온다면, 왁스 사출 온도가 너무 높은 것이므로 보다 낮은 온도를 찾아야 한다.

주물에서도 표면이 거친 현상은 주조의 온도 또는 플 라스크의 온도가 높을 때 나타나는 결함 이며 왁스 사출 적정 압력에서 사출한 모드에서 분리한 패턴의 표면은 매끄러우나, 포크 형상과 같이 갈라지며 패턴이 완전히 주입되지 않는다면, 피드스프루에 문제가 있다 라고 단 정할 수 있다.

피드스프루의 계획된 실험(designed experiment)은 제 품 패턴의 가장 적합한 피드스프루를 찾아내기 위함이며

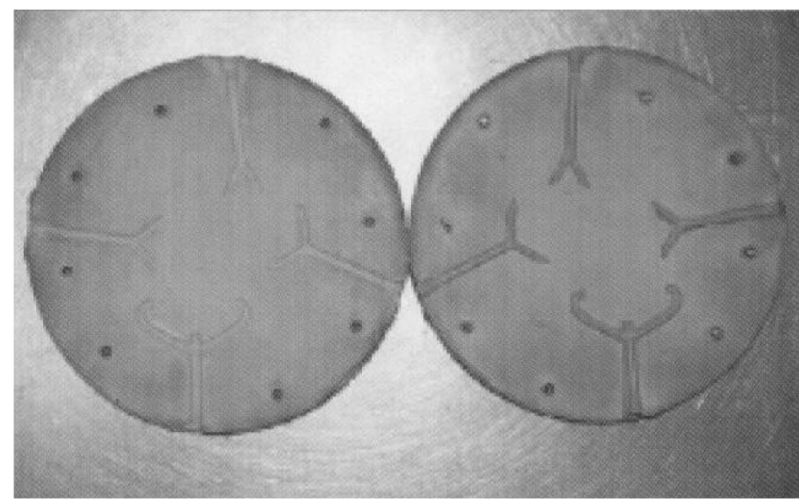

Fig. 12. Feed sprue use rubber mold.

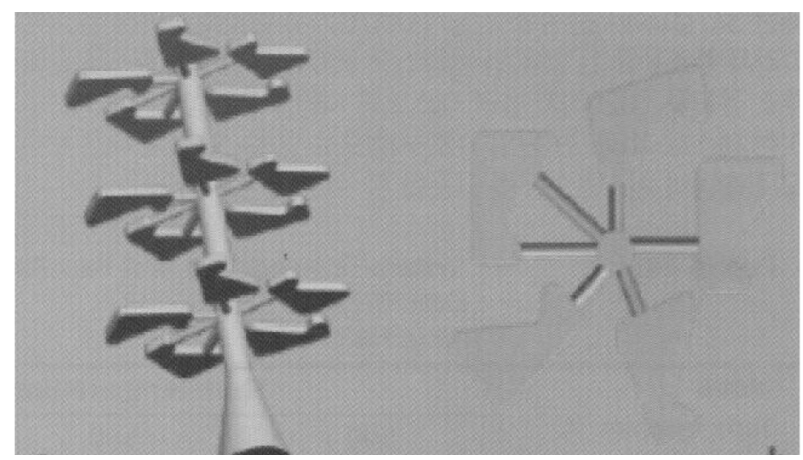

Fig. 13. Feed sprue and wax tree.

앞서 설명한 시스템 온도 테스트와 같은 방법으로 왁스 트리를 만든다.

피드스프루를 만드는 방법은 Fig. 12와 같이 각도와 굵기가 다른 여러 형태의 왁스 피드 스프루를 고무 몰드 로 만든 후 이것을 이용하여 패턴의 크기와 위치를 고려 하여 패턴에 부착한다.

실험에서 중요한 것은 모양과 크기가 동일한 패턴을 사용하는 것이며 Fig. 13과 같이 다섯 개 혹은 여섯 개 의 패턴에 피드스프루 부착하여 메인 스프루에 3 단 정 도로 부착하여 각 층별로 각도와 굵기, 패턴에 부착위치, 부착방법 등을 달리하여 왁스 트리를 만든다.

하나의 플라스크에서 실험을 완성할 수 있으나, 결과 가 만족스럽지 못할 경우, 새로운 방법으로 추가 플라스 크를 만들어 실험하여 최상의 조건을 찾아야 한다.

2) 피드스프루의 위치와 형태

피드스프루는 용탕의 주입 효율성을 높이고 용탕의 요 동(turbulence)을 줄여 완벽한 주조품을 만들기 위한 디 자인이 되어야 한다.

Fig. 14는 동일한 조건(합금, 주조, 트리) 및 동일한 크 기에서 주조된 패턴이다.

Fig. 14의 (1) 제품은 납작한 피드스프루에서 주조 되 었고, (2)와 (3) 두가지 패턴은 테이퍼 라운드 스프루 (tapered round sprue)에서 주조 되어졌다. 


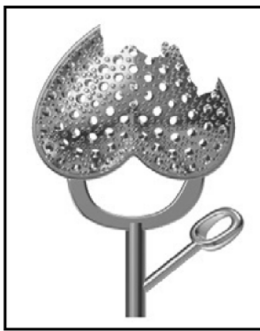

(1)

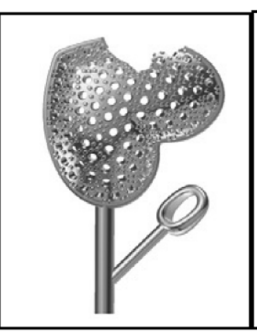

(2)

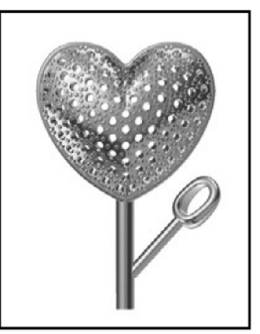

(3)
Fig. 14. A way attach difference design.

또한 하트의 포인트 부분에 피드스프루를 부착하는 것 과 하트의 어깨 부분에 피드스프루를 부착 하였을 때 용 탕의 주입의 차이가 확연히 차이가 남을 알 수 있다.

피드스프루의 위치와 부착방법에 따라 품질에 커다란 차 이가 나며 중앙에 스톤 난집이 있는 나비 모양의 실버 핀 은 이와 같은 피드스프루 연구의 좋은 예라고 할 수 있다.

Fig. 15는 피트스프루의 구성을 변화시켜 실험하였으 며, 싱글 피트스프루를 부착하였을 경우 피트스프루 부 착 점 반대편 고리 부분에 수축기포가 발생 하였다.

Fig. 15 더블은 피트스프루를 추가 하였으나 기포의 발생 위치가 바뀌었고, 기포가 다소 감소 하였으나 만족 할 만한 품질은 아니었다.

Fig. 16 더블은 두 개의 피드스프루로 수직에서 수평 으로 위치를 변경하여 기포는 제거 하였으나, 난집을 지 지하는 갈라진 가닥에 용탕이 완전히 주입되지 않았다.

갈라진 가닥은 용탕의 온도를 높여서 같은 위치에서 완전히 주입시킬 수는 있으나, 표면이 거칠어지는 문제 가 발생하므로 최선의 방법은 아니었다.

또한 Fig. 16의 트리플과 같이 피드스프루를 가운데에

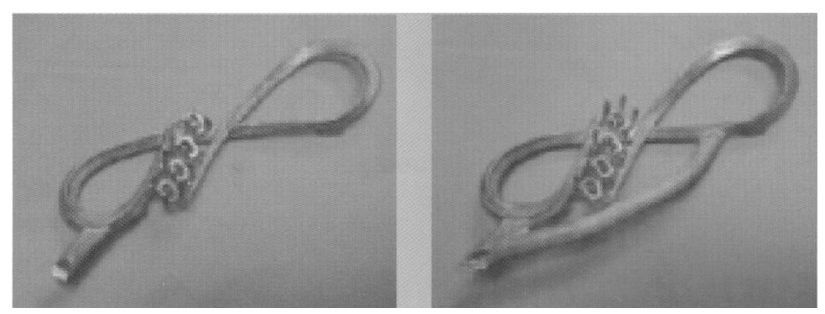

Fig. 15. Feed sprue single, double.

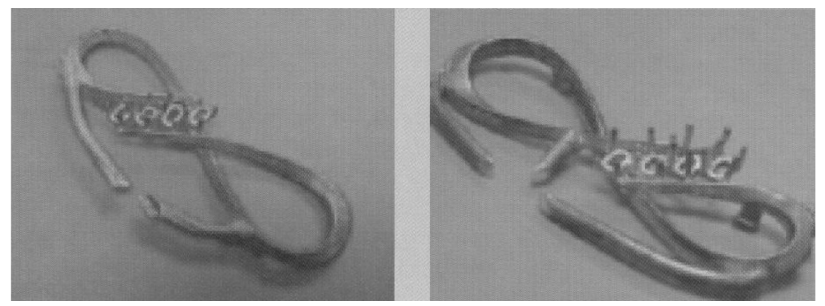

Fig. 16. Feed sprue double, triple.

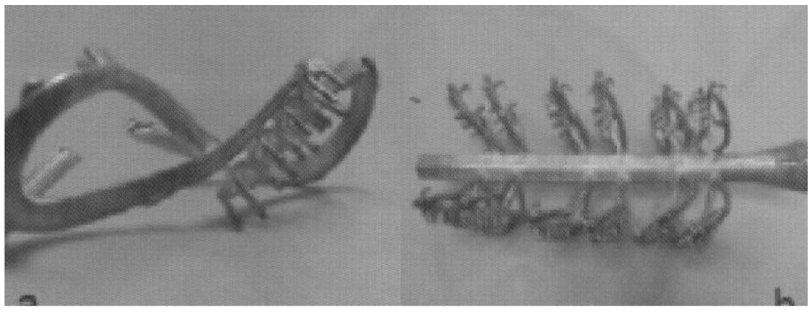

Fig. 17. Feed sprue horizontal attach.

추가한 세 개의 피드스프루를 부착 하였으나, 완전하게 주입 되지는 않았다.

마지막으로 Fig. 17과 같이 두 개의 피드스프루를 수 평으로 부착하고 패턴을 플라스크 벽 쪽으로 향하게 위 치를 변형시키자 좋은 결과를 얻었다.

이상과 같은 실험을 통하여 만족할 만한 결과를 얻었 고, 피드스프루의 위치와 형태, 부착방법에 있어서도 실 험결과에 커다란 차이가 있는 것을 알았으며, 지속적인 연구와 실험이 필요함을 느겼다.

\section{3. 결 론}

정밀주조의 시스템 제작 시 설계한 원형과 가장 근접한 결과물이 나오기까지 무수한 데이터 시험과 시편 제작이 필요한 현실을 비춰볼 때 부분적으로 발생할 수 있는 문 제점들을 데이터화하고 표준화 시킴으로서 새로운 장비에 대한 신속한 적응능력을 가질 수 있도록 하여야 하며 장 비활용능력에 대한 경쟁력을 갖는 것이 매우 중요하다.

본 연구자가 시편제작 실험을 통해서 확인할 수 있었 던 것은 Fig. 12처럼 고무몰드를 이용한 왁스사출 단계 에서부터 피드스프루의 크기 및 부착형태에 대한 테스트 를 반드시 실시하여 완벽한 사출과 최상의 조건을 찾아 내야 하고 Fig. 15, Fig. 16, Fig. 17의 실험처럼 피드스 프루의 갯수를 늘리는 것 보다는 붙이는 위치와 어디에, 어떻게, 몇 개를 붙여야 우수한 결과물이 나오는지의 조 건이 매우 중요하다는 결론을 얻었다.

따라서 정밀주조 공정에서 나타날 수 있는 문제점 중 피드스프루의 형태가 주조 결과물에 중요한 영향을 미칠 수 있다는 결론을 얻었고 이를 데이터 실험과 자료를 바 탕으로 추가적인 연구를 통한 피드스프루의 형태를 표준 화하고 방향을 제시하여 업계에서 많이 활용되는 지침자 료가 될 수 있도록 노력하고자 한다.

\section{참 고 문 헌}

[1] J.-P. Ha, "A study the investment casting process for 
improving of the mechanical properties", Pukyong National University Graduate School, Doctorate Thesis (2005) 24.

[2] Y.-H. Heo, "Chrome-molly steel precision casting mold rotation speed using the vertical centrifugal casting and mechanical properties of the impact on", Yeungnam University Graduate School, PhD thesis (2002) 38.

[3] N.-S. Jo, "A wax sculpture in ceramic alumina by the investment casting flask research", Joe fleet Graduate School Master's Thesis (1995).

[ 4 ] S.-I. Yun, "Design of metal casting process for process analysis", Ph.D. dissertation, Graduate School, Chungnam National University (1995) 55.
[ 5 ] I.-S. Cho, "Investment casting of the molten metal flow and heat transfer in the numerical analysis for the", Master's thesis, Graduate School of Yonsei University (1993).

[6] J.H. Choy, "Effect of anisotropic diffusion coefficient on the evolution of the interface void in copper metallization for integrated circuit", Journal of the Korean Crystal Growth and Crystal Technology 14 (2004) 58.

[ 7 ] C.-S. Park, J.-I. La and D.-Y. Kim, "Synthesis of powders from precursors prepared by precipitation process", Journal of the Korean Crystal Growth and Crystal Technology 12 (2002) 87. 